\title{
Schnapsideen und Maskeraden
}

\section{Bernhard Gurtner}

Dr. med., ehemaliger medizinischer Chefarzt Spital Wetzikon, Mitglied FMH

Desinfektionsmittel, Gesichtsmasken und Schutzanzüge sind in der Pandemie knapp geworden, weil viele Betriebe trotz gesetzlicher Vorschriften zu wenig Reserven bereithalten, vertrauend auf just in time abrufbare Lieferungen. Das hat sich als fatale Illusion erwiesen, geschuldet der Auslagerung der Produktion in asiatische Billigländer. Von dort kommen auch alle Antibiotika, die hier in Packungen mit vertrauenswürdigem Logo maskiert und ohne den Aufdruck Made in China teuer verkauft werden. Sofern vorhanden...

\section{Rituelle Körperverpackung im Operationssaal}

Schnaps und Masken erinnern mich an das erste Praktikum als Unterassistent in einem Landspital. Viele Patienten hatten Alkoholprobleme und litten unter Entzug. Der für Desinfektionen vorrätige reine Alkohol musste wie Morphium gut verschlossen in «Giftschränken» gesichert werden. Fromme Frauen schmuggelten für ihre Männer hochprozentigen Nachschub in die Krankenzimmer, beschriftet als «Weihwasser». Ein zittriger Zirrhotiker liess seine Mogelflasche fallen, wonach die Scherben gut riechbar den wahren Inhalt verraten haben.

Wie erfolgte die Maskierung, unsere allererste Einkleidung als assistierende "Hookholder» vor einer Operation? Weisse Galoschen, parfümiert mit dem Fussschweiss vorgängiger Benützer. Kopfhaube, Mundschutz. Vorderarmwaschung nach ellbögelnd zu bedienender Seifenspendung, ungewohnt kratzborstige Nagelbürstchen. Rituelle Körperverpackung mit grüner OP-Wäsche. Durchschlupf mit gestreckten Armen und geballten Fäusten. Bestenfalls wurden wir von einer OP-Schwester angeleitet, oft aber nur kurz von einem Assistenzarzt instruiert und in den Kreis der Vermummten mitgenommen. Heute gibt es auf Youtube sehr instruktive Lehrfilme, z.B. Einwaschen - Einkleiden der Uni Bern (2015).

Nach Beginn des 2. Weltkriegs wurde 1940 im Entlebuch das Ethanol-Pflichtlager der Eidgenössischen Alkoholverwaltung gebaut: Auf 7,5 Hektar 14 Aussentanks und 56 unterirdische Silos, die Platz für 17 Millionen Liter bieten. Keine Schnapsidee, war doch damit der Nachschub von Alkohol als Desinfektionsmittel auch in Krisenzeiten gesichert. Die Lager wurden 2018 privatisiert. Ethanol wird nun im Ausland gekauft und nicht aus naheliegendem Fallobst im thurgauischen Mostindien oder aus dem Harz heimischer Wälder gewonnen. Immerhin wurden in der jetzigen Notlage in Schweizer Weinkellern, Bierbrauereien und Spirituosenfabriken viele Tausend Liter vorrätiger Getränke zu reinem Alkohol destilliert, eingedampfter Kirsch und Pflümligeist als äusserlich anwendbare Virenkiller.

Schon vor dem Kriegsausbruch hatte der Agraringenieur Werner Oswald in Domat/Ems aus Holzabfällen Bioethanol hergestellt, sein patentiertes Emser Wasser. Die HOVAG (Holzverzuckerungs-AG) lieferte ab 1941 jährlich 98200 Tonnen dieses Äthylalkohols als Treibstoffzusatz, mit dem in der Schweiz etwa 20\% Benzin gespart werden konnte. Bald nach Kriegsende kämpften Tankstellenlieferanten und Automobilverbände gegen die bis 1955 vertraglich gesicherte Subventionierung. Der Bundesrat empfahl vorsorglich eine Verlängerung, unterlag aber in der Volksabstimmung.

\section{Maskenlust und Maskenfrust}

Die in «Ems-Chemie» umbenannte HOVAG wurde 1983 von Christoph Blocher übernommen, der den Konzern nach seiner Wahl zum Bundesrat 2003 an seine forsche Tochter Magdalena übergab. Sie ist in der letzten Nationalratssession als einzige Abgeordnete mit einer Schutzmaske aufgetreten, was ihr als Corona-Maskerade untersagt wurde. Kurz zuvor war die Basler Fasnacht seuchenpolizeilich abgeblasen worden. Maskenlust und Maskenfrust. Die Frauen konservativer Muslime könnten dazu unverhüllt ihre Erfahrungen beitragen.

Falls es in der Schweiz zu einer allgemeinen Maskenpflicht kommt, werden wir lernen müssen, in zwei Metern Distanz rein augenblicklich zu kommunizieren ohne Mithilfe der Mundwinkel, welche sonst averbal unsere Befindlichkeit signalisieren. Doch pressten schon die antiken Schauspieler ihre Stimme vermummt durch eine Maske, das personare prägte Persönlichkeiten: Gäll, kännsch mi nööd!? 